\title{
Early-Life Predictors of Higher Body Mass Index in Healthy Children
}

\author{
Molly M. Lamb a Dana Dabelea ${ }^{a}$ Xiang Yin ${ }^{b}$ Lorraine G. Ogden ${ }^{b}$ \\ Georgeanna J. Klingensmith ${ }^{c}$ Marian Rewers $^{\mathrm{a}, \mathrm{c}}$ Jill M. Norris ${ }^{\mathrm{a}}$ \\ ${ }^{a}$ Department of Epidemiology, ${ }^{b}$ Department of Biostatistics, University of Colorado Denver, and \\ 'Barbara Davis Center for Childhood Diabetes, Aurora, Colo., USA
}

\section{Key Words}

Breastfeeding duration - Infant weight gain .

Diabetes exposure in utero $\cdot$ Birth size $\cdot$ Mediator

\begin{abstract}
Background/Aims: Childhood obesity tracks into adulthood, and may increase diabetes and cardiovascular disease risk in adulthood. Prospective analyses may better define the pathways between early life factors and greater childhood body mass index (BMI), a measure of obesity. Methods: The Diabetes Autoimmunity Study in the Young (DAISY) prospectively follows children from birth that are at increased genetic risk for type 1 diabetes. We examined longitudinal data for 1,178 DAISY subjects (mean age at last follow-up: 6.59 years (range: $2.0-11.5$ years). Birth size and diabetes exposure in utero were collected in the enrollment interview. Infant diet information was collected via interviews throughout infancy. Infant weight gain and childhood BMI were measured at clinic visits. Results: Female gender, diabetes exposure in utero, larger size for gestational age, shorter breastfeeding duration, and more rapid infant weight gain predicted higher childhood BMI. Formal mediation analysis suggests the effect of shorter breastfeeding duration on childhood BMI may be mediated by more rapid infant weight gain. Also, the effect of diabetes exposure in utero on child-
\end{abstract}

hood BMI may be mediated by larger size for gestational age. Conclusion: We identified strong interrelationships between early life factors and childhood BMI. Understanding these pathways may aid childhood obesity prevention efforts.

Copyright $\odot 2009$ S. Karger AG, Basel

\section{Introduction}

The prevalence of overweight among preadolescent US children has more than doubled in the past 25 years, rising from 5 to $14 \%$ in 2 - to 5 -year-olds and from 7 to $19 \%$ in 6 - to 11 -year-olds $[1,2]$. In children and adolescents, being overweight or having a high percentage of body fat is related to cardiovascular disease risk factors $[3,4]$, and higher risk of metabolic syndrome [5]. In addition, childhood overweight and obesity track into adulthood $[6,7]$, and obesity in adulthood increases a person's risk for serious health problems including cancer, stroke, heart disease, type 2 diabetes, and premature death [8]. Therefore, it is important to identify risk factors for childhood obesity.

Most studies of childhood obesity risk factors have categorized obesity outcomes. These categories have included the international body mass index (BMI) stan-

\section{KARGER}

Fax +41613061234 E-Mail karger@karger.ch www.karger.com
(C) 2009 S. Karger AG, Basel

0250-6807/10/0561-0016\$26.00/0

Accessible online at:

www.karger.com/anm
Dr. Jill M. Norris, MPH, PhD

University of Colorado Denver

13001 E. 17th Place, B119, Bldg. 500, Room W3139

Aurora, CO 80045 (USA)

Tel. +1 303724 4428, Fax +1 303724 4489, E-Mail jill.norris@ ucdenver.edu 
dards for childhood overweight and obesity [9], various population percentile cutoffs for overweight and obese, measurements of body fat, and variations on weight/ height. While BMI is considered a reasonable estimation of fatness in children, the use of categories may not be the most appropriate way to examine body size, as health risks may increase linearly with increasing body size. Therefore, we examined childhood BMI as a continuous outcome variable.

Exposure to diabetes [10] or cigarette smoke $[11,12]$ in utero, high birthweight $[13,14]$, rapid weight gain/catchup growth in infancy [13, 15-17], and shorter breastfeeding duration [18-21] have been associated with increased risk of childhood obesity. However, we currently have little understanding of how these early-life risk factors for childhood obesity are related to and affect each other.

Knowledge of the interrelationships between early-life risk factors for higher childhood BMI may help to identify biologic mechanisms that drive higher childhood BMI, and to describe the potential impact of changing modifiable early-life risk factors for higher childhood BMI. Therefore, we explored known early-life exposures for association with higher childhood BMI, and attempted to better define the complex interrelationships between known early-life risk factors and higher childhood BMI.

\section{Methods and Procedures}

\section{Study Population}

The Diabetes Autoimmunity Study in the Young (DAISY) is a prospective study of two groups of young children at increased risk for developing type 1 diabetes [22]. One group consists of unaffected first-degree relatives of patients with type 1 diabetes, identified and recruited in infancy through the Barbara Davis Center for Childhood Diabetes in Denver, Colo., other diabetes care clinics, and the Colorado IDDM Registry. The second group consists of babies born at St. Josephs Hospital in Denver, Colo., and screened by umbilical cord blood samples for diabetes susceptibility alleles in the human leukocyte antigen (HLA) region $[23,24]$. The St. Josephs Hospital newborn population is representative of the Denver metropolitan area general population. Cord blood is sent to Roche Molecular Systems, Inc., Alameda, Calif., for PCR-based HLA class II typing. The details of the newborn screening [22] and follow-up [25] have been published elsewhere.

DAISY subjects complete clinic visits at 9, 15, and 24 months, and annually thereafter up to age 15 . Potential predictors and cohort selection variables were collected as follows: gender, race/ ethnicity (non-Hispanic white or other), maternal education ( $\leq$ or $>12$ years of education), annual household income ( $<$ or $\geq$ USD $30,000)$, mother's age at child's birth, type 1 diabetes status of first-degree relatives, exposure to mother's diabetes in utero (type
1, type 2, gestational, or none), exposure to cigarette smoke in utero (while pregnant with the DAISY child, mother did or did not smoke at least 50 cigarettes), birthweight, and length of gestation were collected in an interview at the time of enrollment. Exclusive breastfeeding duration, total breastfeeding duration, and formula use were recorded in a structured telephone interview conducted by a DAISY staff member at 3, 6, 9, 12, and 15 months of age. Exclusive breastfeeding duration was determined by the reported age at which the infant was exposed to any foods or liquids other than breast milk or water. Weight gain in infancy was calculated as: [(weight, kg, at X years - birthweight, kg)/age in years] for weights measured at the clinic visit that took place between 6 months and 1 year of age (mean age $=0.78$ years). This variable represents how rapidly the child grew in their 1st year, and the units are kg/year. Small, appropriate, and large birthweight for gestational age (lowest 10th percentile, 10th-90th percentile, and top 10th percentile of a national sample, respectively [26]) were determined by reported weeks of gestation and birthweight $(\mathrm{g})$.

Weight was measured at every clinic visit on a scale with a precision of $\pm 0.1 \mathrm{~kg}$. First measurement of height was taken when the child was able to stand cooperatively, around 2 years of age, and annually thereafter. Height was collected using a stadiometer with a precision of $\pm 1 \mathrm{~mm}$. BMI was calculated as weight $(\mathrm{kg})$ / height $(\mathrm{m})^{2}$. Because children that are able to stand cooperatively at very young ages may differ from their peers in terms of growth and development, all BMI measurements collected prior to 2 years of age were eliminated from the dataset to prevent bias.

There were 1,746 DAISY subjects enrolled at birth. Twelve subjects were removed from this analysis because they were autoantibody-positive on their first clinic visit, 408 subjects were removed because they never had a height or weight recorded, 140 subjects were removed due to lack of infant weight gain data, and 8 subjects were removed due to lack of breastfeeding data.

Puberty is a time of hormonal changes which result in rapid nonlinear growth. In order to remove the potentially confusing effects of puberty from our analyses, BMI collected between the ages of 2 and 11.0 for girls, and between the ages of 2 and 11.5 for boys, were used for the outcome. These age cutoffs were obtained from an unrelated analysis, in which self-Tanner staging questionnaires [27] were collected on a separate subset of DAISY children aged $\geq 8$ years $(n=604)$. Of the children that reported being Tanner stage 2 for pubic hair, the age cutoffs listed above represent their median age, by gender.

The DAISY cohort follows children at high risk for developing type 1 diabetes (25\% of DAISY children have the high-risk HLA genotype, compared to $\sim 2.3 \%$ in the general population [22]), and DAISY children are tested for diabetes-related autoantibodies at each clinic visit. In order to remove the unknown effects of the early type 1 diabetes disease process on childhood BMI, we excluded data from all visits at and after the development of islet autoimmunity for the 78 children who developed islet autoimmunity during follow-up.

Thus, 5,668 records collected prospectively on 1,178 DAISY subjects (described in table 1) were used in these analyses. Informed consent was obtained from the parents of each study participant, and assent was obtained from the DAISY children beginning at age 7. The Colorado Multiple Institutional Review Board approved all study protocols. 
Table 1. Description of cohort and univariate associations of potential predictors and higher childhood BMI

\begin{tabular}{|c|c|c|c|c|c|}
\hline Variable & Total & $\begin{array}{l}\text { Mean } \pm S D \\
\text { or \% yes }\end{array}$ & Estimate $^{\mathrm{a}}$ & $\begin{array}{l}\text { Standard } \\
\text { error }\end{array}$ & $\mathrm{p}$ value \\
\hline Age at last follow-up, years & 1,178 & $6.59 \pm 3.10$ & $\mathrm{~N} / \mathrm{A}$ & $\mathrm{N} / \mathrm{A}$ & $\mathrm{N} / \mathrm{A}$ \\
\hline Female sex & 1,178 & $47.3 \%$ & -0.363 & 0.071 & $<0.0001$ \\
\hline Non-Hispanic white ethnicity & 1,178 & $72.1 \%$ & -0.029 & 0.081 & 0.72 \\
\hline \multicolumn{6}{|l|}{ Maternal factors } \\
\hline Maternal age, years & 1,169 & $30.2 \pm 5.65$ & -0.001 & 0.006 & 0.86 \\
\hline Maternal education $>12$ years & 1,178 & $77.6 \%$ & -0.122 & 0.087 & 0.16 \\
\hline Annual income USD <30,000 & 1,145 & $77.7 \%$ & 0.071 & 0.087 & 0.42 \\
\hline \multicolumn{6}{|l|}{ Fetal and perinatal factors } \\
\hline Exposure to cigarette smoke in utero & 1,171 & $9.1 \%$ & -0.069 & 0.125 & 0.58 \\
\hline Exposure to diabetes in utero & 1,178 & $14.7 \%$ & 0.261 & 0.102 & 0.01 \\
\hline \multicolumn{6}{|l|}{ Size for gestational age } \\
\hline Small & 1,178 & $15.6 \%$ & -0.509 & 0.098 & $<0.0001$ \\
\hline Appropriate & 1,178 & $76.4 \%$ & reference & reference & reference \\
\hline Large & 1,178 & $8.0 \%$ & 0.661 & 0.131 & $<0.0001$ \\
\hline \multicolumn{6}{|l|}{ Infant factors } \\
\hline Exclusive breastfeeding duration, months & 1,178 & $1.25 \pm 1.66$ & 0.008 & 0.022 & 0.72 \\
\hline Total breastfeeding duration, months & 1,178 & $6.85 \pm 7.45$ & -0.016 & 0.005 & 0.001 \\
\hline Weight gain in 1 st year of life, $\mathrm{kg} /$ year & 1,178 & $7.01 \pm 1.41$ & 0.322 & 0.024 & $<0.0001$ \\
\hline \multicolumn{6}{|l|}{ Cohort selection factors } \\
\hline HLA DR, DQ 3/4 & 1,178 & $25.3 \%$ & -0.151 & 0.083 & 0.07 \\
\hline First-degree relative with type 1 diabetes & 1,178 & $31.1 \%$ & 0.105 & 0.078 & 0.18 \\
\hline
\end{tabular}

${ }^{a}$ Models adjusted for age and age ${ }^{2}$.

\section{Statistical Analysis}

Childhood BMI was the outcome measure in these analyses. Linear mixed-effects models (SAS v9.1 Proc Mixed procedure) for longitudinal measures were used to identify independent predictors of higher childhood BMI. This modeling approach allows the use of multiple records per subject collected over time, and recognizes intrasubject correlation, such that the model estimates reflect both intrasubject and intersubject effects. Prior to analysis, the procedure discussed by Cnaan et al. [28] was used to determine best-fit polynomials for both the fixed and random age effects. The $-2 \log$ likelihood statistic and plots of the means and standard deviations of the BMI data were used to determine which degree of polynomial in age best described both the fixed and random effects of a model with BMI as the continuous dependent variable. These models distinguish variability between subjects and variability between repeated measurements over time within subjects. These models had unstructured covariance matrices, and between-subject covariance matrices were restricted to be positive definite.

Using the best-fitting univariate model of age as a base model, potential predictors of higher childhood BMI were examined univariately (table 1) and multivariately (table 2). Based on the multivariate results presented in table 2, we then explored the interrelationships between significant potential predictors for which significant correlation, temporal association and likely biologic mechanism suggested that two predictors may be in the same pathway leading to higher childhood BMI. Linear regression and linear mixed models were used to explore for mediators. A proce-
Table 2. Multivariate model of early life risk factors as potential independent predictors of increased childhood BMI

\begin{tabular}{|c|c|c|c|}
\hline Effect & Estimate $^{\mathrm{a}}$ & $\begin{array}{l}\text { Standard } \\
\text { error }\end{array}$ & $\mathrm{p}$ value \\
\hline Female sex & -0.048 & 0.068 & 0.48 \\
\hline Exposure to diabetes in utero & 0.162 & 0.094 & 0.08 \\
\hline \multicolumn{4}{|l|}{ Size for gestational age } \\
\hline Small & -0.544 & 0.091 & $<0.0001$ \\
\hline Appropriate & reference & reference & reference \\
\hline Large & 0.726 & 0.123 & $<0.0001$ \\
\hline \multicolumn{4}{|l|}{ Total breastfeeding duration } \\
\hline months & -0.006 & 0.004 & 0.16 \\
\hline $\begin{array}{l}\text { Weight gain in 1st year of } \\
\text { life, } \mathrm{kg} \text { /year }\end{array}$ & 0.327 & 0.024 & $<0.0001$ \\
\hline
\end{tabular}

a Model adjusted for age and age ${ }^{2}$.

dure to test for mediation has been described previously $[29,30]$. We tested for mediation in our data with fixed exposure variables and multiple outcome measurements per subject.

Mediation analysis is a simple form of structural equation modeling. Our mediation analysis was conducted as follows: (1) 
Fit a linear mixed model predicting the outcome by the independent factor of interest to get the total effect $(\tau)$ of the independent factor on the outcome. (2) Add the potential mediator to the model fit in step 1 to estimate the direct effect $\left(\tau^{\prime}\right)$ of the independent factor of interest adjusted for the potential mediator, and the effect $(\beta)$ of the potential mediator on the outcome. (3) Fit a linear regression model regressing the potential mediator on the independent variable of interest to estimate the effect $(\alpha)$ of the independent factor on the potential mediator.

The indirect effect of the independent factor on the outcome is the difference between the total and direct estimates $\left(\tau-\tau^{\prime}\right)$ and represents the effect of the independent factor on the outcome that works through (is explained by) the mediator. The mediated effect can also be calculated as $\alpha \cdot \beta$ (i.e. $\alpha \cdot \beta=\tau-\tau^{\prime}$ ). This property is useful for testing the significance of the mediated effect (see next paragraph). The direct effect of the independent variable on the outcome is the effect that does not work through the mediator in the adjusted model $(\tau)$. To estimate the percentage of the total effect of the independent factor on the outcome that is mediated through the proposed pathway, the following equation was used: $\left[\left(\tau-\tau^{\prime}\right) / \tau\right] \cdot 100$.

To determine the significance of the mediated effect, the following test statistic was used: $Z=(\alpha \cdot \beta) /$ standard error $(\alpha \cdot \beta)$, where the standard error of $\alpha \cdot \beta,[\operatorname{SE}(\alpha \cdot \beta)]$ was calculated using the Sobel method [31]. A significant Z statistic $(p<0.05)$ was used to indicate significant mediation. A program that estimates the mediation effect can be found online at http://www.people.ku. edu/ preacher/sobel/sobel.htm.

\section{Results}

The DAISY subjects in this analysis were predominantly non-Hispanic white, approximately $47 \%$ female, and had a mean age at last follow-up of 6.59 years. The best-fitting age model ('base model') was quadratic in the fixed effects and random effects. Univariate associations between childhood BMI and early life factors of interest are presented in table 1. Male gender, diabetes exposure in utero, larger size for gestational age, more rapid weight gain in the 1st year of life, and shorter total breastfeeding duration were significantly associated with higher childhood BMI in the univariate models. Exposure to tobacco smoke in utero, exclusive breastfeeding duration, maternal education, mother's age at child's birth, non-Hispanic white ethnicity, family income level, high-risk HLA genotype, and family history of type 1 diabetes were not associated with higher childhood BMI (table 1).

In the multivariate model that included all the early life factors significantly associated with higher childhood BMI, diabetes exposure in utero and total breastfeeding duration were no longer significantly associated with higher childhood BMI (table 2). We suspected these factors were no longer significantly associated with higher childhood BMI because they were closely related to other independent variables in the model. Therefore, we used mediation analysis to explore the interrelationships between these potential predictors of higher childhood BMI for which significant correlation, temporal association and likely biologic mechanism suggested that two predictors may be in the same pathway leading to higher childhood BMI.

We hypothesized that larger size for gestational age was in the pathway of the effect of diabetes exposure in utero on higher childhood BMI. Birth size was correlated with diabetes exposure in utero in this cohort (Spearman correlation coefficient $=0.16, \mathrm{p}<0.0001)$. Mediation analyses suggested that $46 \%$ of the effect of exposure to diabetes in utero on higher childhood BMI may be explained by greater size for gestational age [total effect $(\tau)$ for diabetes exposure in utero: 0.261 , direct effect $\left(\tau^{\prime}\right)$ for diabetes exposure in utero: $0.140, \mathrm{Z}=4.46, \mathrm{p}<0.0001$ ].

We also hypothesized that rapid infant weight gain was in the biologic pathway of the effect of shorter breastfeeding duration on higher childhood BMI. More rapid infant weight gain was inversely correlated with shorter breastfeeding duration in this cohort (Spearman correlation coefficient $=-0.20, \mathrm{p}<0.0001$ ). Mediation analysis suggested that $69 \%$ of the effect of shorter breastfeeding duration on increased childhood BMI may be explained by rapid infant weight gain ( $\tau$ for breastfeeding duration: $-0.016, \tau^{\prime}$ for breastfeeding duration: $-0.005, Z=-5.67$, $\mathrm{p}<0.0001)$.

\section{Discussion}

While a number of early-life risk factors for high childhood BMI have already been identified, the pathways that connect these risk factors are not well understood. We found that gender, diabetes exposure in utero, size for gestational age, weight gain in the first year of life, and total breastfeeding duration (inverse) showed significant association with higher childhood BMI (table 1). Mediation analysis suggested that the protective effect of breastfeeding duration on childhood BMI may be largely mediated by slower infant weight gain, and the increased risk of higher childhood BMI conveyed by exposure to diabetes in utero may be partially explained by greater birth size.

Two hypotheses regarding the observed protective effects of breastfeeding against childhood obesity [18, 19, $21,32]$ have been proposed. The first proposes that the difference in nutritional content between breast milk 
Fig. 1. Potential pathways to higher childhood BMI as defined by mediation analyses. Note that unmeasured confounding factors may bias the direct effects and the mediated effects.

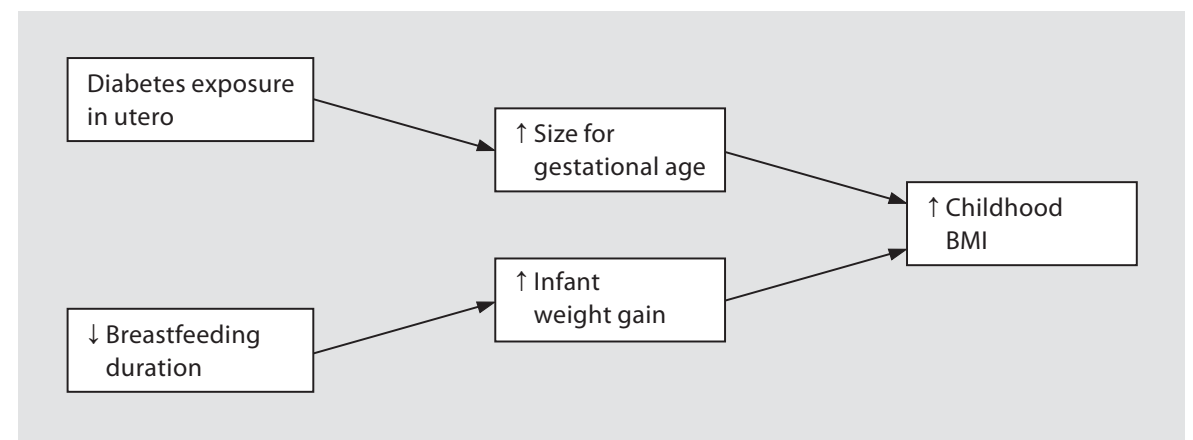

(high fat, low protein) and formula (low fat, high protein) contributes to early adiposity rebound and greater subsequent childhood obesity in formula-fed infants [33]. The second suggests that the protective effect is due to lower plasma concentrations of insulin, a hormone that promotes fat storage, in breastfed infants compared to formula-fed infants [34].

Rapid weight gain in infancy has also been associated with childhood obesity $[13,17]$. An association between breastfeeding duration and rapid infant weight gain has been seen previously [35-37]. We also showed that rapid infant weight gain is a significant mediator of the association between shorter breastfeeding duration and higher childhood BMI ( $p<0.0001$; fig. 1$)$. It is possible that infant feeding patterns may be influenced by rapid infant weight gain. For example, babies that are 'falling off' their growth curve may be weaned due to their mother's or physician's perception of insufficient growth. We hypothesize that the association between rapid postnatal infant growth and increased childhood BMI is due to a diet-induced altered metabolic state in infancy, the effects of which persist throughout childhood.

Exposure to gestational diabetes has been associated with greater fat mass at birth [38], and childhood obesity has been associated with exposure to diabetes in utero $[10,39,40]$. We found that exposure to diabetes in utero was associated with higher childhood BMI, and that greater birth size acted as a partial mediator in this association. It has been hypothesized that exposure to diabetes in utero may lead to childhood obesity via fetal hyperglycemia and hyperinsulinemia. Fetal hyperinsulinemia can act as a growth hormone, leading to larger birth size, and may induce insulin resistance, leading to overgrowth of fat cells and obesity in postnatal life. Other research suggests that exposure to diabetes in utero may lead to childhood obesity in the absence of higher birthweight due to in utero programming effects [41]. This may ex- plain why the mediating effect of higher birthweight does not explain all of the association between exposure to diabetes in utero and higher childhood BMI.

Furthermore, mediator analysis of the subgroup that excluded the 47 subjects exposed to gestational diabetes in utero (no analysis subjects were exposed to type 2 diabetes in utero) estimated that birth size mediated 59\% of the effect of exposure to type 1 diabetes in utero on increased childhood BMI ( $\tau$ for type 1 diabetes exposure in utero: $0.235, \tau^{\prime}$ for type 1 diabetes exposure in utero: $0.096, \mathrm{Z}=4.52, \mathrm{p}<0.0001$; fig. 1$)$. The mediating role of birth size in the pathway between type 1 diabetes exposure in utero and higher childhood BMI has not yet been demonstrated.

Both low birthweight [15] and high birthweight $[13,14$, 17] have been associated with childhood obesity. We found larger size for gestational age, a marker of in utero growth permissiveness, was associated with higher childhood BMI (table 2). Adjustment for infant weight gain strengthened the effect of higher birthweight on higher childhood BMI, suggesting that, although high birthweight infants gain less weight in the 1st year of life, they still remain at higher risk for higher childhood BMI. Similarly, a study in the Pima Indians found that children exposed to diabetes in utero had higher birthweights, slower weight gain ('catch-down growth') in infancy, and subsequent greater childhood obesity [42].

The main strengths of this analysis are the large sample size, the prospective, longitudinal nature of the data, and the long follow-up time. We were able to explore associations and interrelations between known early-life exposures and higher childhood BMI. Study weaknesses include lack of other measures of fat mass and physical activity data. More accurate measures of childhood fat mass may help to more specifically identify the early life risk factors that are most important for preventing chronic disease processes in children. Physical activity may ex- 
plain (low levels of physical activity may result in higher $\mathrm{BMI}$ ), or counteract (via high muscle mass) the potentially ill effects of higher childhood BMI. We were also unable to analyze some known risk factors for higher childhood BMI, such as maternal diet and weight gain during pregnancy. Parental height and weight were not included in this analysis due to concerns that the very low response rate and the self-reported nature of these data would produce an unstable and biased result. While the mediation analysis assumes causality, the observational study design prevents determination of causality. In addition, there may be unmeasured confounders in our mediation analyses (e.g. physical activity, genetics, etc.).

It is possible that a number of the analysis subjects had already started to undergo body changes related to $\mathrm{pu}$ berty. However, a sensitivity analysis revealed that reducing the upper age limit of subjects in the analysis from 11.5 years (boys) and 11 years (girls) down to 9.5 years and 9 years, respectively, did not change the results. Finally, the DAISY population may not be representative of the general population, as enrollment is based on HLA genotype or family history of type 1 diabetes. However, these sampling variables were not associated with this analysis outcome, and we did not include any records that may have been affected by the autoimmune disease process. Therefore, the cohort selection is unlikely to affect the results.
In conclusion, we defined two separate pathways between early life risk factors and higher child hood BMI in a cohort of healthy U.S. children. Our results suggest that infants that are breastfed for a shorter period of time tend to gain weight faster during the 1st year of life, and are subsequently more likely to have higher childhood BMI. Likewise, larger birth size may partially mediate the association between diabetes exposure in utero and higher childhood BMI. Future research should be directed towards better understanding how genetics (such as parental BMI) and fetal exposures (such as weight gain during pregnancy) interact with early life (composition of infant diet, infant weight gain) and childhood diet and physical activity patterns in determining childhood risk of higher BMI. Such research may lead to targeted mother and infant nutritional recommendations that would reduce risk of higher BMI throughout childhood, and thus potentially reduce the risk of obesity-related diseases throughout life.

\section{Acknowledgements}

Research supported by National Institutes of Health grants R01-DK49654, DK32493, Diabetes Endocrine Research Center, and Clinical Investigation and Bioinformatics Core P30 DK 57516.

\section{References}

1 Ogden CL, Flegal KM, Carroll MD, Johnson CL: Prevalence and trends in overweight among US children and adolescents, 19992000. JAMA 2002;288:1728-1732.

-2 Ogden CL, Carroll MD, Curtin LR, McDowell MA, Tabak CJ, Flegal KM: Prevalence of overweight and obesity in the United States, 1999-2004. JAMA 2006;295:1549-1555

- 3 Burke V, Beilin LJ, Simmer K, Oddy WH, Blake KV, Doherty D, Kendall GE, Newnham JP, Landau LI, Stanley FJ: Predictors of body mass index and associations with cardiovascular risk factors in Australian children: a prospective cohort study. Int J Obes Relat Metab Disord 2005;1:15-23.

4 Freedman DS, Dietz WH, Srinivasan SR, Berenson GS: The relation of overweight to cardiovascular risk factors among children and adolescents: the Bogalusa Heart Study. Pediatrics 1999;103:1175-1182.
5 Weiss R, Dziura J, Burgert TS, Tamborlane WV, Taksali SE, Yeckel CW, Allen K, Lopes M, Savoye M, Morrison J, Sherwin RS, Caprio S: Obesity and the metabolic syndrome in children and adolescents. N Engl J Med 2004; 350:2362-2374.

- 6 Serdula MK, Ivery D, Coates RJ, Freedman DS, Williamson DF, Byers T: Do obese children become obese adults? A review of the literature. Prev Med 2005;22:167-177.

-7 Srinivasan SR, Bao W, Wattigney WA, Berenson GS: Adolescent overweight is associated with adult overweight and related multiple cardiovascular risk factors: the Bogalusa Heart Study. Metabolism 1996;45: 235-240

8 US Surgeon General: Overweight and Obesity: Health Consequences. Washington, US Department of Health \& Human Services, 2005.

-9 Cole TJ, Bellizzi MC, Flegal KM, Dietz WH: Establishing a standard definition for child overweight and obesity worldwide: international survey. BMJ 2000;320:1240-1243.
10 Huang JS, Lee TA, Lu MC: Prenatal programming of childhood overweight and obesity. Matern Child Health J 2007;11:461473.

11 von Kries R, Toschke AM, Koletzko B, Slikker W: Maternal smoking during pregnancy and childhood obesity. Am J Epidemiol 2002;156:954-961.

12 Moschonis G, Grammatikaki E, Manios Y: Perinatal predictors of overweight at infancy and preschool childhood: the GENESIS study. Int J Obes 2008;32:39-47.

13 Reilly JJ, Armstrong J, Dorosty AR, Emmett PM, Ness A, Rogers I, Steer C, Sherriff A, Avon Longitudinal Study of Parents and Children Study Team: Early life risk factors for obesity in childhood: cohort study. BMJ 2005;330:1357.

14 Ong KK: Size at birth, postnatal growth and risk of obesity. Horm Res 2006;65:65-69. 
$\checkmark 15$ Ong KK, Ahmed ML, Emmett PM, Preece MA, Dunger DB: Association between postnatal catch-up growth and obesity in childhood: prospective cohort study. BMJ 2000; 320:967-971.

16 Adair LS: Child and adolescent obesity: epidemiology and developmental perspectives. Physiol Behav 2008;94:8-16.

17 Dubois L, Girard M: Early determinants of overweight at 4.5 years in a population-based longitudinal study. Int J Obes Relat Metab Disord 2006;30:610-617.

18 Hediger ML, Overpeck MD, Kuczmarski RJ, Ruan WJ: Association between infant breastfeeding and overweight in young children. JAMA 2001;285:2453-2460.

-19 Mayer-Davis EJ, Rifas-Shiman SL, Zhou L, $\mathrm{Hu}$ FB, Colditz GA, Gillman MW: Breastfeeding and risk for childhood obesity: does maternal diabetes or obesity status matter? Diabetes Care 2006;29:2231-2237.

20 Horta BL, Bahl R, Martines JC, Victoria CG, and World Health Organization: Evidence on the long-term effects of breastfeeding. Systematic reviews and meta-analysis. Geneva, World Health Organization, 2007, pp $1-52$.

-21 Gillman MW, Rifas-Shiman SL, Camargo CA, Berkey CS, Frazier AL, Rockett HR, Field AE, Colditz GA: Risk of overweight among adolescents who were breastfed as infants. JAMA 2001;285:2461-2467.

-22 Rewers M, Bugawan TL, Norris JM, Blair A, Beaty B, Hoffman M, McDuffie RS Jr, Hamman RF, Klingensmith G, Eisenbarth GS, Erlich HA: Newborn screening for HLA markers associated with IDDM: diabetes autoimmunity study in the young (DAISY). Diabetologia 1996;39:807-812.

23 Davies JL, Kawaguchi S, Bennett ST, Copeman JB, Cordell HJ, Pritchard P: A genomewide search for human type 1 diabetes susceptibility genes. Nature 1994;371:130-136.
24 Lambert AP, Gillespie KM, Thomson G, Cordell HJ, Todd JA, Gale EA, Bingley PJ: Absolute risk of childhood-onset type 1 diabetes defined by human leukocyte antigen class II genotype: a population-based study in the United Kingdom. J Clin Endocrinol Metab 2004;89:4037-4043.

25 Norris JM, Barriga K, Klingensmith G, Hoffman M, Eisenbarth G, Erlich HA, Rewers M: Timing of initial cereal exposure in infancy and risk of islet autoimmunity. JAMA 2003 290:1713-1720.

26 Oken E, Kleinman KP, Rich-Edwards J, Gillman MW: A nearly continuous measure of birth weight for gestational age using a United States national reference. BMC Pediatr 2003;8:6.

27 Taylor SJ, Whincup PH, Hindmarsh PC, Lampe F, Odoki K, Cook DG: Performance of a new pubertal self-assessment questionnaire: a preliminary study. Paediatr Perinat Epidemiol 2001;15:88-94.

28 Cnaan A, Laird NM, Slasor P: Using the general mixed model to analyze unbalanced repeated measures and longitudinal data. Stat Med 1997;16:2349-2380.

29 Baron RM, Kenny DA: The moderator-mediator variable distinction in social psychological research: conceptual, strategic, and statistical considerations. J Pers Soc Psychol 1986;51:1173-1182.

30 MacKinnon DP, Krull JL, Lockwood CM: Equivalence of the mediation, confounding and suppression effect. Prev Sci 2000;1:173181.

31 Sobel ME: Asymptotic confidence intervals for indirect effects in structural equation models; in Leinhardt S (ed): Sociological Methodology. Washington, American Sociological Association, 1982, pp 290-293.

32 Gillman MW, Rifas-Shiman SL, Berkey CS, Frazier AL, Rockett HR, Camargo CA, Field AE, Colditz GA: Breast-feeding and overweight in adolescence. Epidemiology 2006; 17:112-114.

-33 Rolland-Cachera MF, Deheeger M, Maillot M, Bellisle F: Early adiposity rebound: causes and consequences for obesity in children and adults. Int J Obes Relat Metab Disord 2006; 30:S11-S17.
34 Lucas A, Sarson DL, Blackburn AM, Adrian TE, Aynsley-Green A, Bloom SR: Breast vs. bottle: endocrine responses are different with formula feeding. Lancet 1980;1:12671269 .

35 Kramer MS, Guo T, Platt RW, Vanilovich I, Sevkoskaya Z, Dzikovich I, Michaelsen KF, Dewey K: Feeding effects on growth during infancy. J Pediatr 2004;145:600-605.

>36 Ong KK, Preece MA, Emmett PM, Ahmed ML, Dunger DB, ALSPAC study team: size at birth and early childhood growth in relation to maternal smoking, parity and infant breast-feeding: longitudinal birth cohort study and analysis. Pediatr Res 2002;52:863867.

-37 Scholtens S, Gehring U, Brunekreef B, Smit HA, de Jongste JC, Kerkhof M, Gerritsen J, Wijga AH: Breastfeeding, weight gain in infancy, and overweight at seven years of age: the prevention and incidence of asthma and mite allergy birth cohort study. Am J Epidemiol 2007;165:919-926.

38 Catalano PM, Thomas A, Huston-Presley L, Amini SB: Increased fetal adiposity: a very sensitive marker of abnormal in utero development. Am J Obstetr Gynecol 2003;189: 1698-1704.

39 Dabelea D, Hanson RL, Lindsay RS, Pettitt DJ, Imperatore G, Gabir MM, Roumain J, Bennett PH, Knowler WC: Intrauterine exposure to diabetes conveys risks for type 2 diabetes and obesity: a study of discordant sibships. Diabetes 2000;49:2208-2211.

40 Malcolm JC, Lawson ML, Gaboury I, Lough G, Keely E: Glucose tolerance of offspring of mother with gestational diabetes mellitus in a low-risk population. Diabet Med 2006;23: 565-570.

41 Pettitt DJ, Knowler WC, Bennett PH, Aleck KA, Baird HR: Obesity in offspring of diabetic Pima Indian women despite normal birth weight. Diabetes Care 1987;10:76-80.

-42 Touger L, Looker HC, Krakoff J, Lindsay RS, Cook V, Knowler WC: Early growth in offspring of diabetic mothers. Diabetes Care 2005;28:585-589. 


\section{Erratum}

In the article 'Early-Life Predictors of Higher Body Mass Index in Healthy Children' by Lamb et al. (Ann Nutr Metab 2010;56:16-22) an error occurred in the abstract. The first section of results should read 'Male gender, diabetes exposure in utero, larger size for gestational age, shorter breastfeeding duration, and more rapid infant weight gain predicted higher childhood BMI.' 